\title{
Apparatus note: A modified WGTA for children'
}

BRUCE A. OLSON, henRY A. CROSS AND REESA M. VAUGHTER

TEXAS TECHNOLOGICAL COLLEGE

A discrimination apparatus for use with children is described. This particular modification of the WGTA enhances the likelihood that $S$ will attend to the stimulus objects since it permits the use of the traditional formboard. The apparatus described retains the simplicity of operation of the drawertype WGTA while avoiding several limitations of this latter instrument.

The Wisconsin General Test Apparatus (WGTA) has become increasingly important in experimental investigations of learning in children (e.g., House \& Zeaman, 1963), and there can be no question as to its value as a major tool in the comparative psychology of the future (Meyer, Treicher \& Meyer, 1965).

Modifications of the WGTA for children typically employ a drawer-type presentation of stimuli instead of the traditional formboard (House \& Zeaman, 1958). This is done to eliminate the necessity of manipulating an opaque screen between $\mathrm{E}$ and $\mathrm{S}$, but this arrangement has the undesirable effect of restricting S's view of the stimulus objects. The leading edge of the drawer must of necessity be higher than the objects employed and, as a consequence, acts as a visual barrier. This means that not only is there an initial delay in exposure to the stimuli, but the objects are also more quickly obscured as the drawer is withdrawn from $S$ at the conclusion of a trial.

Since the role of attention is judged to be of great importance in discrimination problems with children Ss (House \& Zeaman, 1963), every effort should be made to maximize the time available to $S$ for viewing the stimuli both before and after his response. The modification described herein permits the use of a standard formboard but does not entail a hand-operated opaque screen. By purely mechanical means it has been possible to overcome the limitations of a drawer-type WGTA while retaining its simplicity and efficiency.

An isometric representation of the apparatus is shown in Fig. 1. Since dimensions may be adjusted to $E$ 'S needs, an extensive description is not given. The base of the apparatus is $36 \times 36$ in., and the upright partition, which is located $15 \mathrm{in.} \mathrm{from} \mathrm{the} \mathrm{edge} \mathrm{of} \mathrm{the} \mathrm{base} \mathrm{facing}$ $\mathrm{S}$, stands $24 \mathrm{in}$. high. There is an $18 \times 18$ in. one-way screen located in the upright partition which is equipped with a light on S's side.

The formboard is $18 \times 18 \times 3 / 4$ in. and rides on four standard drawer rollers which are inset in the underside of the formboard. On each side of the formboard are two identical risers which are shaped like normal curves and reach a maximum height of $2-1 / 2$ in. These risers are $1 / 2$ in. wide and function to raise and lower a floating wooden partition when the formboard is extended to $S$. The floating partition moves vertically in guides affixed to the upright portion of the apparatus and is

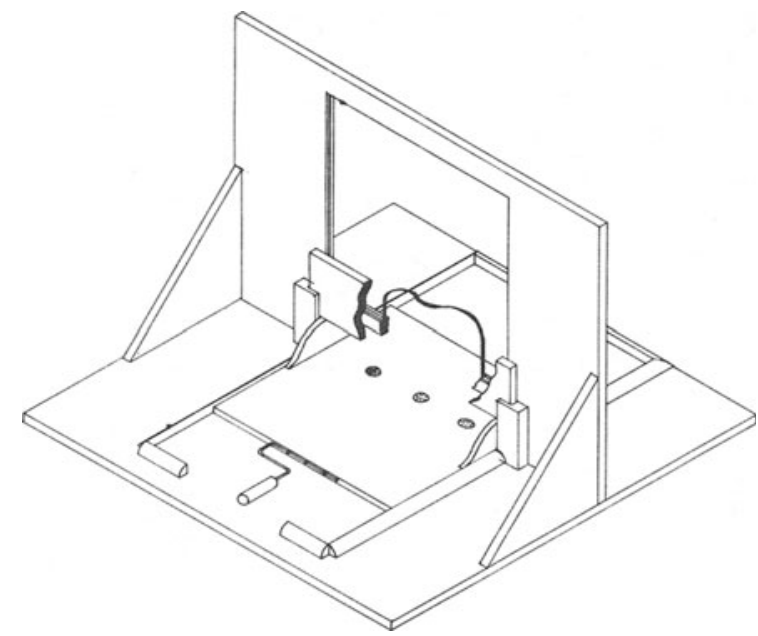

Fig. 1.

in a "down" position when $E$ is placing objects on the formboard. The floating partition is guided over the risers by two standard rollers attached to its underside at the points where contact is made with the risers. When the formboard is extended to $S$, the partition moves up and the objects are unobstructed as they pass through the opening in the lower portion of the upright. When the formboard is fully extended the partition is again in the down position. By gluing a small rubber strip along the bottom edge of the floating partition (except for the area at which the rollers are in contact with the risers), the tiny light gap between formboard and partition can be effectively closed and the apparatus can be made almost noiseless.

In recent studies (Cross \& Vaughter, 1966) this apparatus has been utilized for several thousand trials with no attendant problems. In the opinion of the authors this modification of the WGTA represents an advance over other manually-operated modifications with which we are familiar.

\section{References}

Cross, H. A., \& Vaughter, R. M. The Moss-Harlow effect in children as a function of age. Unpublished manuscript, 1966.

House, B. J., \& Zeaman, D. A comparison of discrimination learning in normal and mentally defective children. Child. Develpm., $1958,29,411-416$.

House, B. J., \& Zeaman, D. Miniature experiments in the discrimination learning of retardates. In L. P. Lipsitt \& C. C. Spiker (Eds.), Advances in child development and behavior. Vol. I. New York: Academic Press, 1963.

Meyer, D. R., Treichler, F. R., \& Meyer, P. M. Discrete-trial training techniques and stimulus variables. In A. M. Schrier, H. F. Harlow, \& F. Stollnitz (Eds.), Behavior of nonhuman primates. Vol. I. New York: Academic Press, 1965.

\section{Note}

1. The authors are grateful to Stanley $\mathrm{H}$. Holgate for drawing the apparatus. 